\title{
Ondokuz Mayıs Üniversitesi'nde 2 yıllık süreçte baş boyun kitlelerinde ince iğne aspirasyon biyopsisi deneyimimiz - 50 vaka
}

Fine needle aspirationbiopsy experiences of head and neck masses in a two years period in Ondokuz Mayis University -50 cases

\author{
Senem Çengela, Cem Bayraktar*a, Ahmet Aksoy ${ }^{a}$, Sinan Atmaca ${ }^{a}$, İlkser Akpolat ${ }^{\text {b }}$ \\ ${ }^{a}$ Ondokuz Mayıs Üniversitesi Tıp Fakültesi, Kulak Burun Boğaz Anabilim Dalı, Samsun, Türkiye \\ ${ }^{b}$ Ondokuz Mayls Üniversitesi Tıp Fakültesi, Patoloji Anabilim Dalı, Samsun, Türkiye
}

\begin{tabular}{|c|c|}
\hline \multicolumn{2}{|c|}{ MAKALE BİLGÍLERİ } \\
\hline \multicolumn{2}{|c|}{ Makale geçmişi } \\
\hline Geliş tarihi & $: 09 / 01 / 2012$ \\
\hline Kabul tarihi & $: 15 / 01 / 2012$ \\
\hline
\end{tabular}

\section{* Yazışma Adresi:}

Cem Bayraktar

Ondokuz Mayıs Üniversitesi Tıp Fakültesi,

Kulak Burun Boğaz Anabilim Dalı,

Kurupelit, Samsun, Türkiye

e-posta: cem_dr23@hotmail.com

\section{Anahtar Kelimeler: \\ Boyunda kitle \\ İnce iğne \\ Aspirasyon biopsisi \\ Sitoloji \\ Histopatoloji \\ Biopsi tekniği}

\section{Keywords:}

Neck mass

Fine needle

Aspiration biopsy

Cytology

Histopathology

Biopsy technique

\section{ÖZET}

$\mathrm{Bu}$ çalışmada baş ve boyun kitlelerinde ince iğne aspirasyon biyopsilerini histopatolojik sonuçlar ile karşılaştırıp, diagnostik olarak sensitivite ve spesifitesini saptamayı hedefliyoruz. Ağustos 2008-Temmuz 2010 tarihleri arasında kliniğimize baş boyun bölgesinde yerleşik kitle yakınması ile başvuran ve cerrahi eksizyon öncesi İnce İğne Aspirasyon Biyopsisi (İ̈AB) uygulanan 50 hasta retrospektif olarak incelendi. Araştırma kapsamına alınan 50 hastanın 26'sı (\% 52) erkek, 24'ü (\% 48) kadındı. Ortalama yaş: $54,3 \pm 17,8$ ve median yaş: 55 (18 yaş- 84 yaş) idi. Histopatolojik olarak malign etiyoloji saptanan 29 (\% 58) hastanın; 10'unda (\% 34,4) IİAB tanıs1 "malignite pozitif", 4 hastada (\% 13,7) "malignite negatif" ve 15 hastada $(\% 51,7)$ ise "kategorize edilemeyen "ve/ veya "değerlendirme için yetersiz" olarak raporlandı. Yirmi bir hastada (\% 42) benign histopatolojik sonuç elde edilmekle birlikte, bu hastaların hiçbirinde malignite yönünden pozitif İİB sonucu izlenmedi. On iki hastada (\% 57,1) "malignite negatif" sonuç bulunurken, 9 hastada (\% 42,8) "kategorize edilemeyen" ve/veya "değerlendirme için yetersiz" olarak saptandı. İIAB ile tanı konabilen malign etiyolojilerden en sı yassı hücreli kanser, benign etiyolojilerden ise nonspesifik inflamasyon izlendi. İIAB'in duyarlılı̆̆ 1 $\% 71,4$, spesifitesi $\% 100$ ve doğrululuk oranı ise \% 84,6 olarak bulundu. Literatür ile karşılaştırıldığında düşük düzeyde duyarlılık ve doğruluk oranları saptanması; İİB değerlendirilmesinde yeterince yetkinleşilememesinden, biyopsilerin farklı kişilerce alınmasından ve görüntüleme yöntemlerinden faydalanılmamasından kaynaklanıyor olabilir.

J. Exp. Clin. Med., 2012; 29:131-133

\section{ABSTRACT}

The aim of this study was to compare the histopathological results of fine needle aspiration biopsy (FNAB)s in head and neck masses, and to evaluate the specifity and sensitivity for diagnosis. Data were obtained retrospectively from 50 patients who referred to our clinic with head and neck masses before surgery between August 2008 and July 2010. Twenty six patients $(52 \%)$ were male and $24(48 \%)$ were female. The mean and median ages of the patients were $54.3 \pm 17.8$ and 55 respectively. Twenty nine patients $(58 \%)$ had malignant histopathological etiology; in 10 patients $(34.4 \%)$ FNAB was reported as "positive malignity", 4 patients $(13.7 \%)$ were reported as "negative malignity" and 15 patients $(51.7 \%)$ were reported as "non-categorize" and/or "insuficient for assesment". Twenty one patients (42\%) had benign etiology; in 12 patients (57.1\%) FNAB was reported as "negative malignity", 9 patients $(42.8 \%)$ were "non-categorize" and/or "insufficient for assessment". There were no positive malignant reports obtained in the benign group. Squamous cell carcinoma is the most common diagnosis in malignant etiologies and nonspecific inflammation is the most common diagnosis in benign etiologies, which could be diagnosed with FNAB. FNAB method sensitivity was $71.4 \%$, specifity was $100 \%$ and accuracy rate was found $84.6 \%$. When compared with the literature, determination of the low level sensitivity and accuracy rates could be because biopsies were taken by different persons and the imaging techniques were not use.

J. Exp. Clin. Med., 2012; 29:131-133

(C) $2012 \mathrm{OMU}$ 


\section{Giriş}

İnce iğne aspirasyon biyopsisi (İ̈AB); enfeksiyöz, tümöral ve konjenital birçok farklı etiyolojinin neden olabileceği boyunda kitle yakınması ile başvuran hastalarda, tanı ve tedavi sürecinde yol gösterici olmaktadır. İlk kez 1847 yılında Kun tarafından tanımlanmış, fakat 1930'lu yıllarda Martin ve Ellis'in çalışmaları sonucu rutin olarak kullanılmaya başlanmıştır (Önder ve ark., 1994; Demir ve ark., 2006).

Baş boyun bölgesi lezyonlarının değerlendirilmesinde İİB; yararl, güvenli ve doğruluğu kanıtlanmış bir yöntemdir (Platt ve ark., 1990; Fulciniti ve ark., 1997). Yine hamileler, çocuklar ve kalp yetmezliği gibi yüksek riskli hastalarda da tekniğin kolaylıkla uygulanabilir oluşu bir başka avantajdır (Fried ve Ferenc, 1993; Önder ve ark., 1994; Fulciniti ve ark., 1997). Bu çalışmamızda 2 yıllık süreçte kliniğimize başboyun kitle yakınması ile başvuran ve İİA uyguladığımız hastaların sitolojik ve histopatolojik sonuçlarını duyarlılık, özgüllük ve doğruluk yönünden karşıllaştırmayı amaçladık.

\section{Gereç ve yöntem}

Ağustos 2008-Temmuz 2010 tarihleri arasında kliniğimize (OMÜ Tip Fakültesi KBB ABD) baş boyun bölgesinde yerleşik kitle yakınması ile başvuran ve cerrahi eksizyon öncesi İIAB uygulanan 50 hasta retrospektif olarak incelendi. Tüm hastalara poliklinik şartlarında ve farklı hekimler tarafindan IİAB uygulandı. Biyopsi alınırken 25 gauge iğne ve $10 \mathrm{cc}$ 'lik disposable enjektörler kullanıldı. Biyopsi bölgesi antiseptik solüsyonla temizlendikten sonra enjektör pistonu 1cc hava dolacak kadar çekildi. Kitle içine girdikten sonra birkaç kez aynı doğrultuda ileri-geri hareketi yapılarak iğne içine pasif olarak sitolojik materyal girmesi sağlandı (Şek. 1).

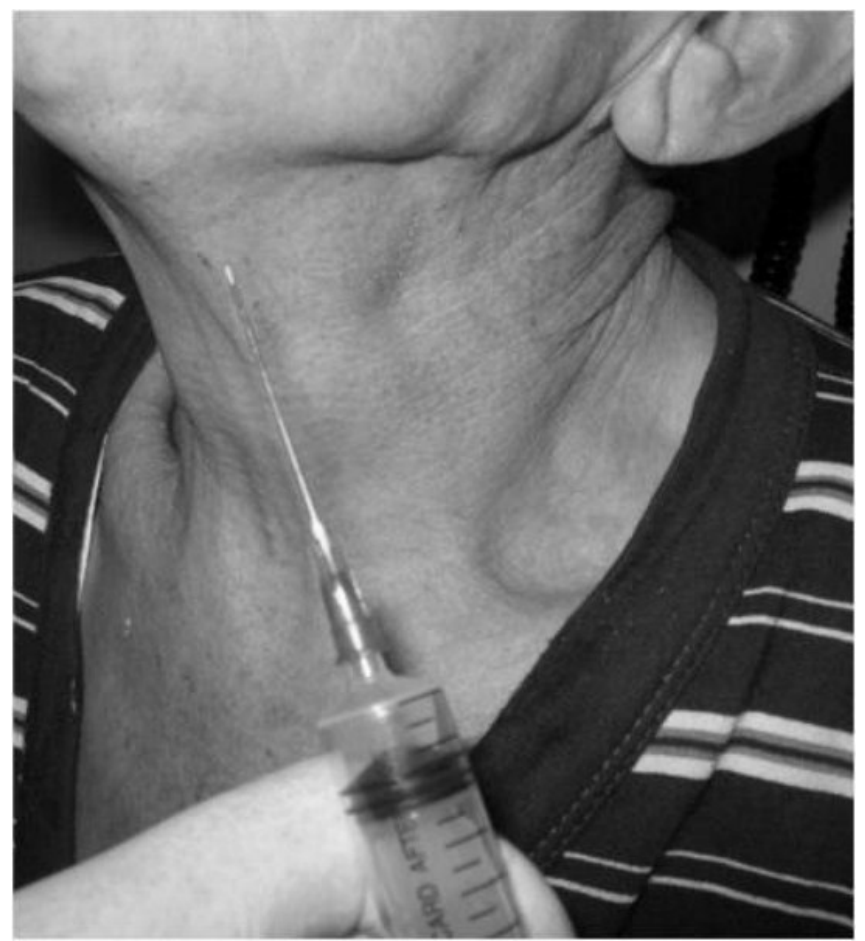

Şek. 1. Piston içine hava çekildikten sonra girişim uygulanması

Ardından lam üzerine materyal basınçla püskürtüldü, iğne ucu çıkarılıp tekrar enjektör hava ile doldurulduktan sonra aynı iğne ucu takılarak yeni bir lam üzerine basınçla püskürtüldü (Şek. 2, 3).

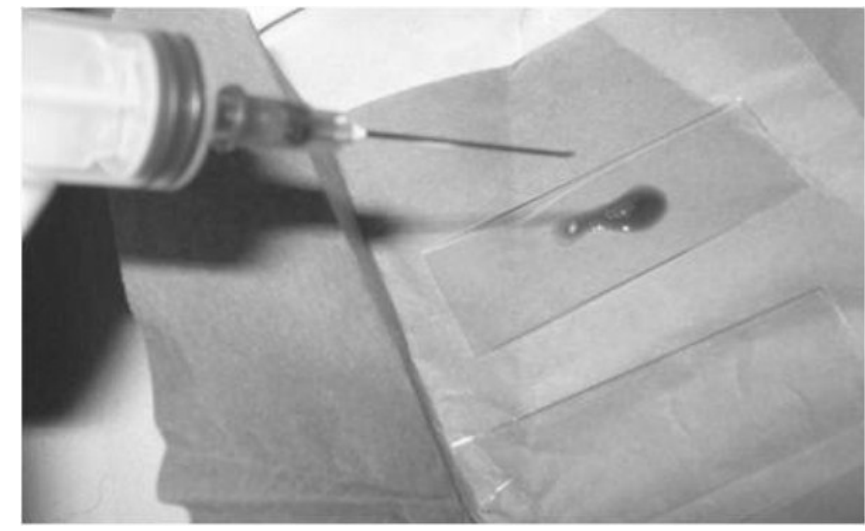

Şek. 2. Sitolojik materyalin lam üzerine püskürtülmesi

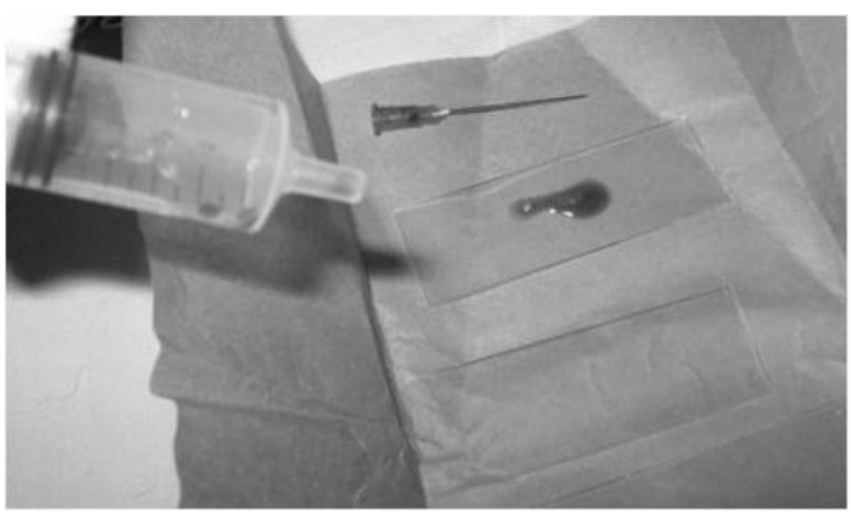

Şek. 3. İlk püskürtme işleminden sonra iğnenin çıkarılıp enjektöre tekrar hava çekilmesi

Her iki lam üzerine temiz lamlar konarak yayma yapıldı. Bunlardan bir tanesi alkol ile fikse edilip, diğeri de havada kurutuldu. Her hastaya en az 2 kez girişim uygulandı ve aspirasyonlardan ikişer adet yayma yapıldı. Çalışmaya alınan hiçbir hastaya görüntüleme eşliğinde biyopsi uygulanmadı. Tüm materyaller aynı patoloji kliniği tarafından değerlendirildi. Aspirasyon biyopsi sonuçları; "malignite pozitif", "malignite negatif", "kategorize edilemeyen" ve "değerlendirme için yetersiz" olarak 4 grupta yorumlandı.

\section{Bulgular}

50 hastanın 26'sı (\% 52) erkek, 24'ü (\% 48) kadındı. Ortalama yaş: $54,3 \pm 17,8$ (SD) (18 y1l-84 yıl) ve median yaş: 55(min 18y-max 84y) idi. Histopatolojik olarak malign etiyoloji saptanan 29 (\% 58) hastanın; 10'unda (\% 34,4) İIAB tanis1 "malignite pozitif", 4 hastada (\% 13,7) "malignite negatif" ve 15 hastada (\% 51,7) ise "kategorize edilemeyen "ve/ veya "değerlendirme için yetersiz" olarak raporlandı. Yirmi bir hastada (\% 42) benign histopatolojik sonuç elde edilmekle birlikte, bu hastaların hiçbirinde malignite yönünden pozitif İIAB sonucu izlenmedi. On iki hastada (\% 57,1) "malignite negatif" sonuç bulunurken, 9 hastada (\% 42,8) "kategorize

Tablo 1. İİB sonuçları ile histopatolojik sonuçların karşılaştırılması

\begin{tabular}{|c|c|c|}
\hline \multirow[b]{2}{*}{ (İIAB Sonuçları) } & \multicolumn{2}{|c|}{ Histopatolojik Sonuçlar } \\
\hline & $\begin{array}{l}\text { Malign } \\
(\mathrm{n}=29)\end{array}$ & $\begin{array}{c}\text { Benign } \\
(\mathrm{n}=21)\end{array}$ \\
\hline Malignite Pozitif & $10(\% 34,4)$ & - \\
\hline Malignite Negatif & $4(\% 13,7)$ & $12(\% 57,1)$ \\
\hline Kategorize Edilemeyen & $10(\% 34,4)$ & $5(\% 23,8)$ \\
\hline Değerlendirme Yetersiz & $5(\% 17,2)$ & $4(\% 19,0)$ \\
\hline
\end{tabular}


edilemeyen" ve/veya "değerlendirme için yetersiz" olarak saptand1 (Tablo 1).

İİB ile tanı konabilen malign etiyolojilerden en sık yassı hücreli kanser, benign etiyolojilerden ise nonspesifik inflamasyon izlendi (Tablo 2, 3).

\section{Tablo 2. İİA ile tanı konulabilen malign olguların dağılımı}

\begin{tabular}{lcc} 
Tanı & Sayı & $\begin{array}{c}\text { Yüzde } \\
(\%)\end{array}$ \\
\hline Yassı Hücreli Karsinom & 6 & 12 \\
Tiroid papiller Karsinom & 1 & 2 \\
Nöroendokrin Tümör & 1 & 2 \\
Lenfoma & 1 & 2 \\
Malign Epitelyal Tm & 1 & 2 \\
Tablo 3. İ̇AB ile tanı konulabilen benign olguların dağılımı & Yüzde \\
Tanı & Sayı
\end{tabular}

Malign kitlelerin \% 34,4'üne ( $\mathrm{n}=10)$, benign kitlelerin ise $\%$ 23.8'ine $(n=5)$, tüm olguların ise \% 30'una $(n=15)$ İİAB ile tanı konulabildi. Galen ve Gambino metodu kullanılarak duyarlılık, spesifite ve doğrulukları belirlendi (Galen ve Gambino, 1975). İİAB'in duyarlılı̆̆ $1 \%$ 71,4, spesifitesi (=özgüllüğü) \% 100 ve doğruluk oranı ise \% 84,6 olarak bulundu. Malign kitlelerin \% 34,4'üne ( $\mathrm{n}=10)$, benign kitlelerin ise \% 23.8 'ine $(n=5)$, tüm olguların ise $\% 30$ 'una $(n=15)$

\section{Tartışma}

İIAB ucuz ve kolay uygulanabilir bir yöntemdir. Lokal anestezi gerektirmez. Literatürde İİAB'in doğruluk oranı \% 90'ın altında değildir. Yalancı pozitif sonuçlar ise oldukça azdır (Sismanis ve ark., 1980; Önder ve ark., 1994). Bu nedenle ele gelen baş boyun kitlelerinde araştırmada ilk adım olarak kabul edilmektedir (Cummings ve ark., 2007). Flynn ve ark.'nın cerrahi uyguladıkları 135 hasta üzerinde yaptıkları çalışmada preoperatif İİAB ile duyarlılık \% 82 ve spesifite \% 99 olarak saptanmış, yine \% 5 hastada non-diagnostik sonuç bulunmuştur (Flynn ve ark., 1990). Fulciniti ve ark.'nın 218 baş boyun tümörlü hastaya uyguladıkları İİA'lerde \% 95,7 duyarlılık ve $\% 100$ spesifite bulunmuş olup sadece 2 hastada $(\% 3,4)$ yanlış negatif ve 6 hastada da (\% 10,2) non-diagnostik sonuç elde edilmiştir (Fulciniti ve ark., 1997). Köybaşığlu ve ark.'nın baş boyun kitlesi ile başvuran 369 hastaya İIAB uygulamış; \% 93,4 duyarlılık, \% 81,8 spesifite ve \% 88,8 doğruluk oranı belirlemişlerdir (Köybaşığlu ve ark., 2004).

Bizim çalışmamızda ise duyarlılık \% 71,4, spesifite $\% 100$ ve doğruluk oranı ise \% 84,6 olarak bulundu. Dört hastada ( $\%$ 8) yanlış negatif, 9 hastada (\% 18) non-diagnostik sonuç elde edildi. Tüm olguların ise sadece 30 'una $(n=15)$ İİAB ile tanı konulabildi. Literatür ile karşılaştırıldığında duyarlılık ve doğruluk oranlarımızda belirgin düşüklük olduğu görüldü. Spesifite oranı ise literatür ile uyumlu görünmekte ki bu da İ̇AB'ler yanlış pozitifliğin hemen hemen hiç gözlenmemesi ile örtüşmektedir. Kliniğimizde bu oranların düşük çıkması, İİA uygulayan kişilerin farklılığı ve deneyimsizliği ile ilişkili olabilir. İIAB'nin etkinliğini artırmada; biyopsiyi alan kişinin deneyimi, görüntüleme yöntemlerinin kullanılması ve örnek alınır alınmaz örneğin sitopatolog tarafından yeterliliğinin değerlendirilmesi çok önemlidir (Aygenç ve ark., 2001). Tüm bunların non-diagnostik tanı oranımızı $(n=9, \% 18)$ arttıran etkenler olduğu kanısındayız.

Sonuç olarak, literatür ile karşılaştırıldığında düşük düzeyde saptanan duyarlılık ve doğruluk oranlarının; ekip olarak çalışılmasında (klinisyen, sitopatolog, radyoloji) eksiklikten, biopsilerin hep farklı ve tecrübesi az kişilerce alınmasından ve görüntüleme yöntemlerinden yeterince faydalanılmamasından kaynaklanıyor olduğunu düşünmekteyiz. Bu düşünceyi gelecekte, yukarıda saydığımız koşullarda alınan İİB sonuçlarının değerlendirileceği bir çalışmayla açığa kavuşturmayı da planlamaktayız. Kullanımı kolay, maliyeti az ve hastayı olası invazif girişimlerden uzak tutabilecek olan İ̇AB yönteminin daha etkin bir şekilde kliniğimizde kullanılması için yapılan bu ve benzeri çalışmalarla daha da yerleşik bir metot olarak tercih edilmesi sağlanacaktır.

\section{KAYNAKLAR}

Aygenç, E., Çelikkanat, S., Kaymakçı, M., 2001. İnce iğne aspirasyon biyopsisinin tanısal değeri. KBB ve BBC Dergisi. 9, 93-96.

Cummings, C.W., Flint, P.W., Haughey, B.H., Robbins, K.T., Thomas, J.R., Harker, L.A., Richardson, M.A., Schuller, D.E. 2007. Cummings Otolaringoloji-Baş ve Boyun Cerrahisi. 4. Baskı. Güneş Tıp Kitabevi.

Demir, D., Akçam, M.T., Karakoç, Ö. 2006. Baş boyun kitlelerinde ince iğne aspirasyon biyopsisinin tanısal değeri. KBB-Forum. 5, 5-11.

Flynn, M.B., Wolfson, S.E., Thomas, S., 1990. Fine needle aspiration biopsy in clinical management of head and neck tumors. J. Surg. Oncol. 44, 214-217.

Fried, M.P., Ferenc, A.J., 1993. Image guided intervention for diagnosis and treatment of disorders of the head and neck. Laryngoscope. 103, 924-927.

Fulciniti, F., Califano, L., Zupi, A., Vetrani, A., 1997. Accuracy of fine needle aspiration biopsy in head and neck tumors. J. Oral Maxil. Surg. 55, 1094-1097.

Galen, R.S., Gambino, S.R. 1975. Beyond normality. The predictive value and efficiency of medical diagnosis. New York, NY, John Wiley \& Sons.

Köybaşıŏlu, F., Özakkoyunlu, S., Kocatürk, S., Önal, B.Ü., 2004. Baş boyun kitlelerindeki ince iğne aspirasyon sitolojisi sonuçlarımız. KBBForum. 3, 31-34.

Önder, T., Aktaş, D., Günhan, Ö., Özkaptan, Y., 1994. Baş ve boyun kitlelerinde ince iğne aspirasyon biyopsisi. K.B.B. ve Baş Boyun Cerrahisi Dergisi. 2, 32-37.

Platt, J.C., Davidson, D., Nelson, C.L., 1990. Fine needle aspiration biopsy : An analysis of 89 head and neck casses. J. Oral Maxil. Surg. 48, 706-707.

Sismanis, A., Strong, M.S., Merriam, J., 1980. Fine needle aspiration biopsy diagnosis of neck masses. Otolaryng. Clin. N. Am. 13, 421-429. 